\title{
Адсорбционные, ионообменные и бактериостатические свойства кремнеземов, модифицированных катионами алюминия и серебра
}

\author{
Котельникова Т.А. \\ Московский государственньй университет им. М.В.Ломоносова, Москва \\ Поступила в редакцию 14.03.2018 г.
}

DOI: https://doi.org/10.17308/sorpchrom.2018.18/508

Изучены адсорбционные, ионообменные и бактериостатические свойства однородно широкопористого силохрома, поверхность которого модифицирована ионами алюминия и серебра. Показано, что модифицированные кремнеземные сорбенты неоднородны и несут на своей поверхности высокоактивные сорбционные центры разной природы, способные к адсорбции как полярных, так и неполярных веществ. Результаты микробиологического исследования показали, что адсорбция микроорганизмов на такой поверхности приводит к необратимому бактериостазу за счет изменения вторичной и третичной структуры биополимеров. Установлено, что дополнительное модифицирование алюмосиликата ионами серебра существенно не меняет его адсорбционных и бактериостатических свойств. Кремнеземы, модифицированные алюмосиликатными центрами, можно успешно использовать для обеззараживания питьевой воды, исключая при этом вероятность интоксикации серебром.

Ключевые слова: Адсорбенты, обеззараживание воды, примеси, модифицирование, ионы алюминия и серебра, газовая хроматография, ионный обмен, микробиологическое исследование, бактериостаз.

\section{Adsorption, ion-exchange and bacteriostatic properties of silica modified with silver oxide}

\author{
Kotelnikova T.A. \\ Lomonosov Moscow State University. Moscow
}

\begin{abstract}
For disinfection of drinking water, silica synthesized on the basis of chemically pure, homogeneous and broad - porous industrial silochrome $\mathrm{C}-120$ by modifying its surface with aluminum cations is proposed. This adsorbent carrying on its surface a broad range of sorption centers, capable of different types of intermolecular interactions, exhibits a high sorption activity in relation to substances or modeling of possible impurities in drinking water: n. alkanes, aromatic hydrocarbons, their chlorinated derivatives, alcohols, ketones, aldehydes, amines. Qualitative and quantitative assessment of the nature of sorption centers is given on the basis of the results obtained by gas chromatography and acid - base titration. Microbiological studies using Pseudomonas aeruginosa and Escherichia coli showed that broad porous silica of which surface had been modified with aluminosilicate centers can be used for disinfection of drinking water, and to be a successful alternative silver-containing bakteriostatikami. Adsorption of the microorganism in the reactive surface of the aluminosilicate carbonyl or amino groups of the peptide, and part of the radical of amino acids capable of forming with these centres of the hydrogen and salt links. At the same time, they replace the intramolecular hydrogen bonds existing in the protein molecule, which leads to a change in the secondary and tertiary structure of biopolymers.the Undeniable advantage of adsorbents of this kind is that the destruction of microorganisms on their surface is irreversible, and in addition, the probability of intoxication with silver is excluded.
\end{abstract}


Keywords: adsorbents, disinfection of water, impurities, modification, aluminum and silver ions, gas chromatography, ion exchange, microbiological study, bacteriostasis.

\section{Введение}

Проблему очистки и обеззараживания питьевой воды в настоящее время разрешают многими способами: обработкой ультрафиолетом, озонированием, хлорированием. Наиболее распространенный способ - фильтрация с использованием серебросодержащих адсорбентов [напр.,1]. Серебро обладает бактериостатическим действием, т.е. способностью сдерживать рост и размножение бактерий. В растворе бактериостатическое действие серебра может проявиться уже при концентрации от 0,003 мкг/л и зависит от вида бактерии и времени воздействия. Гарантированное обеззараживание от основного круга бактерий имеет место при концентрациях серебра 50-150мкг/л. При использовании адсорбентов, поверхность которых модифицирована наночастицами серебра или его нерастворимыми солями, процесс бактериостаза микроорганизмов, которые накапливаются в фильтре, протекает на поверхности адсорбента. Однако ток очищаемой воды может смывать с поверхности наночастицы металла, а катионы жесткости - вытеснять катионы серебра, создавая в очищаемой воде многократное превышение ПДК. Поверхность постепенно теряет свои бактерицидные свойства, так как «серебряный» бактериостаз обратим, и при удалении серебра бактерии опять начинаю расти [2]. При этом серебро это - тяжелый металл, в [3] серебру присвоен класс опасности 2, высоко опасный, и ПДК составляет 50 мкг/л. Как большинство тяжелых металлов, серебро медленно выводится из организма и при его постоянном поступлении может накапливаться, вызывая ряд заболеваний.

В работе рассмотрена возможность использования для обеззараживания питьевой воды силохрома, поверхность которого модифицирована оксидом алюминия [4]., как альтернативы серебросодержащим адсорбентам - бактериостатикам,

\section{Эксперимент}

Объекты исследования. Синтез. Методы исследования. При синтезе адсорбента - бактериостатика исходили из того, что он должен обладать высокой механической прочностью, достаточно большой поверхностью и широкими порами, доступными микроорганизмам и большим молекулам, и высоким адсорбционным потенциалом по отношению к веществам разной природы, способным как к специфическим, так и неспецифическим взаимодействиям [5]

В качестве матрицы использовали промышленный - химически чистый однородно широкопористый пиролитический гидрофильный кремнезем C-120. Структурные характеристики: средний диаметр пор, $d=200-300 \AA$, суммарный объем пор $v_{\Sigma}=1.2 \mathrm{~cm}^{3} / \Gamma, S_{\text {уд }}=158 \mathrm{~m}^{2} / \Gamma$.

Образец C-Al получен на основе C-120 путем пропитки его раствором нитрата алюминия и последующим термолизом при $200^{\circ} \mathrm{C}$. Приготовленный таким образом силохром с привитыми алюмосиликатными центрами содержал $1.65 \mathrm{mac \%} \mathrm{Al}_{2} \mathrm{O}_{3}$, или 2мкмоль $\mathrm{Al} / \mathrm{M}^{2}$. Образец $\mathrm{C}-\mathrm{Al}-\mathrm{Ag}^{+}$получен нанесением путем ионного обмена из 0,5н раствора $\mathrm{AgNO}_{3}$ ионов серебра на C-Al.

Структурные характеристики C-Al и C-Al- $\mathrm{Ag}^{+}$: средний диаметр пор, $d,=200$ $300 \AA$, суммарный объем пор, $v_{\Sigma},=1.1 \mathrm{~cm}^{3} / \Gamma$, удельная поверхность, $S_{\text {уд }}=160 \mathrm{~m}^{2} / \Gamma$.

Наибольшее практическое применение имеют фильтры, в которых в качестве адсорбента - носителя серебра используют активированный уголь. В работе, для 
сравнения, рассмотрен активированный кокосовый уголь SUNG INDUSTRIAL CO., модифицированный наночастицами и катионами серебра, используемый в фильтрах фирмы «Барьер», образец АУ. АУ - умеренно гидрофильный адсорбент, содержит серебро в форме наночастиц, диаметром $d=20$ нм. Структурные характеристики: $S_{\text {уд }}=1090 \mathrm{~m}^{2} / \Gamma$, из которых на макро - и мезопоры, доступные для сорбции большим молекулам и микроорганизмам, приходится всего $100 \mathrm{~m}^{2} / г$. Общий объем пор $v_{\Sigma}=0.47 \mathrm{~cm}^{3} / \Gamma$, что также значительно меньше $v_{\Sigma}$ для использованных нами кремнеземов [6 и 7].

Сорбционные свойства материалов изучали методом нелинейной газовой хроматографии [8]. Хроматографические измерения проводили на газовом хроматографе ЛХМ-8МД с детектором по теплопроводности (катарометр), ток моста 100ма при температуре опыта $180^{\circ} \mathrm{C}$. Скорость газа-носителя - гелия выбирали в интервале, в котором характеристики удерживания не зависели от расхода газаносителя (35-45 см³/мин), что соответствует равновесной области процесса.

При описании природы поверхности адсорбента оперировали изотермами $a=f(p)$ и $V=f(a)$, рассчитанными из определенных в опыте базовых характеристик: концентрации сорбата в адсорбенте, а, соответствующего ей равновесного давления пара в газовой фазе, $p$, и удерживаемого объема, $V$. Зависимости $a(p)$ и $V(a)$ с высокой степенью точности (коэффициент корреляции $\mathrm{R} \rightarrow 1$ ) описывают полиномы 2-ой и 3-ей степени. Из них рассчитывали изостерические величины удерживаемого объема, $V(10,20)$, и концентрацию сорбата на поверхности сорбента $a(50,100,200)$ для фиксированных значений $a$ и $p$.

В хроматографических опытах в качестве тестовых адсорбатов - молекулярных зондов (м.з.) использованы вещества - возможные примеси в воде и моделирующие примеси, способные к различным видам межмолекулярных взаимодействий и индицирующие адсорбционные центры определенной природы: алканы, арены, их галогенопроизводные, спирты, кетоны, и амины.

Для того, чтобы оценить как изменяется емкость и сорбционная активность адсорбента при модифицировании его поверхности по отношению к данному веществу, рассчитывали отношения $a_{\text {м.3. }} / a(50,200,100)$ и $V_{\text {м.3. }} / V(10,20)$, где $a_{\text {м.3. и }}$ $a(50,200,100)$ - значения концентрации сорбата на поверхности модифицированного образца и на поверхности С-120 или АУ, соответственно, при равновесном давлении

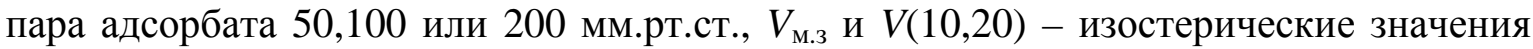
удерживаемого объема адсорбата для модифицированного образца и С-120 и АУ при его концентрации 10 и 20 мкмоль/г.

В режиме хроматографического опыта оценивали концентрацию активных сорбционных центров, способных при $180^{\circ} \mathrm{C}$ необратимо сорбировать амины (белки, пептиды), когда с помощью молекулярных зондов отслеживается изменение адсорбционной активности по мере отравления поверхности аминами.

Концентрацию поверхностных обменных центров определяли путем кислотноосновного титрования: 0.2 г адсорбента заливали $20 \mathrm{~cm}^{3} 0.01$ н раствора $\mathrm{KOH}$, выдерживали в течение суток, отбирали аликвоту $\left(10 \mathrm{~cm}^{3}\right)$ контактного раствора и титровали 0.01 н раствором $\mathrm{HCl}$ с использованием в качестве индикатора метилоранжа.

Молекулярно-биологические исследования проводили в Микробиологической лаборатории ИАЛ АО «БВТ БАРЬЕР РУС».

\section{Обсуждение результатов}

Асорбционные свойства по результатам хроматографических измерений. Как показано в [4] модифицирование поверхности силохрома С-120 катионами алюми-

Котельникова Т.А. / Сорбционные и хроматографические процессы. 2018. Т. 18. № 2 
ния вызывает многократное увеличение сорбции как специфически, так и неспецифически сорбирующихся веществ (табл. 1): в 2-3 раза возрастает сорбция и удержиавние неполярного н.гексана, в 5-6 раз возрастают характеристики удерживания ароматических веществ, сорбирующихся за счет как неспецифических, так и специфических сил с преобладанием последних за счет высокой поляризуемости и квадрупольного момента.

Таблица 1 . Значения $a_{\text {м.3. }} / a(50,100,200)$ и $V_{\text {м.3. }} / V(10,20)$ н.гексана, бензола, метанола, этанола и воды для адсорбентов C-Al относительно C-120 и AУ, C-Al /C-120 и $\mathrm{C}-\mathrm{Al} / \mathrm{AУ}$, и C-Al-Ag ${ }^{+}$относительно C-120 и АУ, C-Al-Ag ${ }^{+} / \mathrm{C}-120$ и C-Al-Ag ${ }^{+} / \mathrm{AV}^{-}$

\begin{tabular}{|c|c|c|c|c|c|}
\hline \multicolumn{2}{|c|}{$\begin{array}{l}\text { адсорбенты } \\
\text { адсорбат }\end{array}$} & $\mathrm{C}-\mathrm{Al} / \mathrm{C}-120$ & $\mathrm{C}-\mathrm{Al}-\mathrm{Ag} / \mathrm{C}-120$ & $\mathrm{C}-\mathrm{Al} / \mathrm{AY}$ & C-Al-Ag/AY \\
\hline \multirow{2}{*}{ H. $\mathrm{C}_{6} \mathrm{H}_{14}$} & $a_{\mathrm{M} \cdot 3} / a(200)$ & 2.5 & 2.0 & 1.1 & 1.0 \\
\hline & $V_{\mathrm{M} .3} / V(10)$ & 2.8 & 1.9 & 1.2 & 1.1 \\
\hline \multirow[b]{2}{*}{$\mathrm{C}_{6} \mathrm{H}_{6}$} & $a_{\mathrm{M} .3} / a(50)$ & 5.0 & 3.5 & 1.1 & 1.2 \\
\hline & $V_{\mathrm{M} .3 .3} / V(10)$ & 5.5 & 3.7 & 1.4 & 1.5 \\
\hline \multirow{3}{*}{$\mathrm{CH}_{3} \mathrm{OH}$} & $a_{\mathrm{M} .3} / a(50)$ & 11.1 & 11.9 & 1.2 & 1.2 \\
\hline & $V_{\mathrm{M} .3} / V(10)$ & 22.15 & 28.0 & 1.7 & 2.1 \\
\hline & $V_{\text {м.3. }} / V(20)$ & 20.2 & 25.2 & 1.2 & 1.5 \\
\hline \multirow{2}{*}{$\mathrm{C}_{2} \mathrm{H}_{5} \mathrm{OH}$} & $a_{\mathrm{M} .3 .} / a(50)$ & 13.0 & 5.2 & 1.3 & 1.6 \\
\hline & $V_{\mathrm{M} .3} / V(10)$ & 14.3 & 15.5 & 1.8 & 2.3 \\
\hline \multirow{2}{*}{$\mathrm{H}_{2} \mathrm{O}$} & $a_{\mathrm{M} .3} / a(100)$ & 12.5 & 16.4 & 3.5 & 4.7 \\
\hline & $V_{\mathrm{M} .3} / V(20)$ & 26.0 & 42.9 & 4.2 & 4.6 \\
\hline
\end{tabular}

Особенно значительное увеличение емкости и сорбционной активности имеет место для полярных веществ, воды и спиртов: их концентрация на поверхности и значения $V$ увеличивается более чем в 10 раз. При этом значительно увеличивается размытие и асимметрия пиков, что указывает на резкое увеличение неоднородности поверхности. Следует отметить также появление у модифицированных образцов появление каталитической активности в реакциях дегидратации и изомеризации спиртов и альдегидов, за которые ответственны сильные кислотные центры [4]. На основании этого следует допустить, что поверхность силохрома, модифицированная оксидом алюминия, несет широкий спектр активных сорбционных центров разной природы. Это гидроксилы матрицы, сильнейшие кислотные алюмосиликатные апротонные (льюисовские) и протонные (бренстедовские) центры и среднекислотные льюисовские и бренстедовские центры дегидроксилированных и гидроксилированных участков оксида алюминия [9]. Замена части протонных центров алюмосиликата на катион серебра, образец C-Al- $\mathrm{Ag}^{+}$, несколько увеличивает гидрофильность адсорбента. При этом для углеводородов сорбция и удерживание снижаются, а для полярных веществ имеет место некоторый рост.

Кислотные центры на поверхности - центры специфической адсорбции полярных сорбатов способны вступать в процесс ионного обмена. По результатам кислотно-основного титрования концентрация иоообменных центров на поверхности силохрома С-120 в результате ее последовательного модифицирования оксидом алюминия и катионами серебра возрастает с 2.0 до 3.6 (образец C-Al) и далее - до 4.0 мкмоль/г (образец C-Al- $\mathrm{Ag}^{+}$). Кремнеземы C-Al и C-Al- $\mathrm{Ag}^{+}$способны необратимо сорбировать триэтиламин, ТЭА, который моделирует аминокислоты, пептиды, белки, даже в условиях хроматографического опыта при $180^{\circ} \mathrm{C}$. Они могут сорбироваться за счет образования аминогруппами солевой связи с сильнокислотными протонными центрами и за счет донорно-акцепторной связи с апротонными алюмосиликат- 
ными центрами. Концентрация необратимо сорбированного при $180^{\circ} \mathrm{C}$ ТЭА для образцов C-Al и C-Al- $\mathrm{Ag}^{+}$составляет 2-4 мкмоль/м².

Адсорбционные характеристики $\mathrm{C}-\mathrm{Al}$ и $\mathrm{C}-\mathrm{Al}-\mathrm{Ag}^{+}$по отношению к возможным примесям находятся на уровне и даже несколько превосходят таковые для промышленного активированного угля (табл. 1).

Микробиологические исследования. Основным показателем микробиологического состояния питьевой воды согласно действующим нормативным документам [2] является Общее Микробное Число (ОМЧ) - количество мезофильных бактерий в $1 \mathrm{~cm}^{3}$ воды. В воде централизованного водоснабжения ОМЧ не должно превышать $50 К О Е / \mathrm{cm}^{3}$, где КОЕ - колониеобразующая единица. ОМЧ определяли по Pseudomonas aeruginosa (Ps. aeruginosaa) или синегнойная палочка, «госпитальная инфекция», грамотрицательнаябактерия, аэроб, способна длительное время сохраняться и размножаться во влажной атмосфере и воде. Определяли также ОКБ - содержание Общих Колиформных Бактерий по Escherichia coli, E.coli, кишечной палочке. Бактериостатическую активность образцов испытывали в статическом и динамическом режимах.

\section{Статический режим (Таблица 2):}

Таблица 2. Результаты микробиологического исследования кремнеземов в статическом режиме

\begin{tabular}{|c|c|}
\hline Анализируемый образец & $\begin{array}{c}\text { ОМЧ } \\
\text { Модельный раствор }\end{array}$ \\
\hline \multirow{2}{*}{$\mathrm{C}-\mathrm{Al}$} & \multicolumn{2}{|c|}{ Мембранная фильтрация, КОЕ/100см ${ }^{3}$} \\
\hline \multirow{2}{*}{$\mathrm{C}-\mathrm{Al}-\mathrm{Ag}^{+}$} & 6 (He Ps. aeruginosa) \\
\cline { 2 - 2 } & 1 (He Ps. aeruginosa) \\
\cline { 2 - 2 } & 13 (He Ps.aeruginosa) \\
\hline
\end{tabular}

Контролируемый показатель: ОМЧ.ОМЧ определяли методом мембранной фильтрации в $100 \mathrm{~cm}^{3}$, на неселективной питательной среде. Модельный раствор асептически приготовлен из стерильной воды с добавлением чистой культуры Pseudomonas aeruginosa, $100 \mathrm{KOE} / 100 \mathrm{~cm}^{3}$.

Согласно ТЗ МбЛ М-7/17 0.5 г сорбента помещали в $250 \mathrm{~cm}^{3}$ модельного раствора, при непрерывном перемешивании выдерживали 15 мин. Далее - последующий посев мембранной фильтрацией в двух повторах на неселективной среде. Время опыта - 72 часа.

Согласно данным экспертизы посев мебранной фильтрацией при $34^{\circ} \mathrm{C}$ мо-

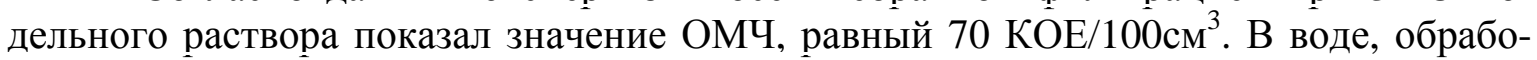
танной эспериментальными сорбентами $\mathrm{C}-\mathrm{Al}$ и $\mathrm{C}-\mathrm{Al}-\mathrm{Ag}^{+}$, рост бактерий Pseudomonas aeruginosa, которыми был контаминирован модельный раствор, отсутствует. Но при этом наблюдали наличие немногочисленного роста желтых и бесцветных бактерий, «Не Ps. aeruginosa», изначально не присутствовавших в модельном растворе. Известно [2,10], что Pseudomonas aeruginosa на твердых питательных средах диссоциирует на R-, S-. и М- формы, которые вирулентными не являются. Ими могут быть продукты диссоциации Ps. aeruginosa на поверхности адсорбентов $\mathrm{C}-\mathrm{Al}$ и $\mathrm{C}-\mathrm{Al}-\mathrm{Ag}^{+}$.

Таким образом, адсорбция синегнойной палочки на реактивной поверхности адсорбентов C-Al и C-Al- $\mathrm{Ag}^{+}$, на нескольких центрах разной природы приводит либо к гибели бактерии, либо, в незначительной части к мутации в непатогенную формy. 
Динамический режим (Таблица 3): Контролируемые показатели: ОМЧ, ОКБ.

Таблица 3. Результаты микробиологического исследования кремнеземов в динамическом режиме

\begin{tabular}{|c|c|c|c|}
\hline $\begin{array}{c}\text { Анализируемый } \\
\text { образец }\end{array}$ & Точка отбора & $\begin{array}{c}\text { ОМЧ } \\
\text { Мебранная фильтра- } \\
\text { ция, КОЕ/см }{ }^{3}\end{array}$ & $\begin{array}{c}\text { ОКБ } \\
\text { Мебранная фильтра- } \\
\text { ция, КОЕ/см}{ }^{3}\end{array}$ \\
\hline Модельный раствор & 1 & 80 & 110 \\
\hline \multirow{3}{*}{$\mathrm{C}-\mathrm{Al}$} & Исх.обсемен. & 1 & 0 \\
\hline & 1 дм $^{3}$ & 12 & 10 \\
\hline & 2 дм $^{3}$ & 24 & 25 \\
\hline \multirow{3}{*}{$\mathrm{C}-\mathrm{Al}-\mathrm{Ag}^{+}$} & Исх. обсемен. & 2 & 0 \\
\hline & 1 дм $^{3}$ & 4 & 5 \\
\hline & 2 дм $^{3}$ & 18 & 13 \\
\hline
\end{tabular}

ОМЧ определяли методом глубинного посева в $1 \mathrm{~cm}^{3}$ на неселективной питательной среде МПА. ОКБ определяли методом мембранной фильтрации на селективной среде Хромокульт. Модельный раствор: стерильная вода с Escherichia coli,

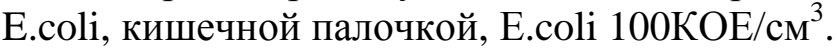

Испытание адсорбента: через сорбент массой 3 г, помещенный в стеклянную колонку с внутренним диаметром $\sim 15$ мм (высота слоя $\sim 6$ см) и пористым фильтром из спеченного стекла в нижней части с помощью перистальтического насоса пропускали модельный раствор. Скорость фильтрации $60 \mathrm{~cm}^{3} /$ мин. Ресурс -2 дм³ $^{3}$.

Эффективность фильтрации в динамическом режиме:

Понижение концентрации микроорганизма на: Адсорбент C-Al: 1 дм³ по показателю ОМЧ - 85, 2 дм $^{3}-70 \%, 1$ дм $^{3}$ по показателю ОКБ - 91, 2 дм $^{3}-77 \%$. Адсорбент C-Al-Ag ${ }^{+}: 1$ дм $^{3}$ по показателю ОМЧ - 95, 2 дм $^{3}-78 \%, 1$ дм $^{3}$ по показателю ОКБ - 95, 2 дм ${ }^{3}-88 \%$.

Таким образом, использование адсорбентов C-Al и C-Al- $\mathrm{Ag}^{+}$позволяет произвести глубокую очистку питьевой воды от кишечной палочки, получить значение ОМЧ, гораздо ниже ПДК.

\section{Заключение}

Результаты исследования адсорбционных и ионообменных свойств показали, что кремнезем, модифицированный оксидом алюминия, несет на своей поверхности, широкий спектр сорбционных центров, способных к межмолекулярным взаимодействиям разного вида. Такой адсорбент, проявляет высокую сорбционную активность по отношению к веществам, являющимся или моделирующим возможные примеси в питьевой воде: н.алканам, ароматическим углеводородам, их хлорпроизводным, спиртам, кетонам, альдегидам, аминам.

Результаты микробиологических исследований позволяют утверждать, что механизм обеззараживания питьевой воды с использованием кремнеземов, поверхность которого модифицирована алюмосиликатными центрами, принципиально отличен от механизма обратимого «серебряного» бактериостаза. При адсорбции микроорганизма на реактивной поверхности алюмосиликата карбонильные или аминогруппы пептидного вида, а также часть радикала аминокислот способны образовывать с сорбционными центрами водородные и солевые связи. При этом они подменяют существующие в белковой молекуле внутримолекулярные водородные связи, что приводит к необратимому изменению вторичной и третичной структуры биополимеров [11]. Несомненным достоинством адсорбентов такого рода является то, что 
деструкция микроорганизмов необратима, в отличие от серебряных бактериостазов, и вероятность интоксикации серебром исключена.

Автор благодарит сотрудника Микробиологической лаборатории ИАЛ АО «БВТ БАРЬЕР РУС» Родионову С.А. за выполнение микробиологических испытаний.

\section{Список литературы}

1. Способ обеззараживания питьевой воды. Патент на изобретение №2381182. Золотухина Е.В., Кравченко Т.А., Ферапонтов Н.Б., Гриднева Е.В., Грабович М.Ю. Патентообладатель: Государственное образовательное учреждение высшего профессионального образования «Воронежский государственный университет» (RU). Дата регистрации: 21.04.2008. Номер заявки: 2008115682/15.

2. Атлас по медицинской микробиологии, вирусологии и иммунологии. Под ред. А. А. Воробьева, А. С. Быкова. М. Медицинское информационное агентство. 2003. С. 60.

3. ГОСТ 2874-82 Вода питьевая, гигиенические требования и контроль за качеством. СанПиН 2.1.4.1116-02.

4. Котельникова Т.А. // Сорбционные $u$ хроматографические прочессы. 2017. Т. 17. № 5. С. 916-922.

5. Грег С., Синг К. Адсорбция, удельная поверхность, пористость. Под ред. ч.-к. АН СССР Чмутова К.В.. М. Мир. 1970. 225 с.

\section{References}

1. Sposob obezzarazhivaniya pit'evoj vody. Patent na izobretenie №2381182. Zolotukhina E.V., Kravchenko T.A., Ferapontov N.B., Gridneva E.V., Grabovich M.YU. Patentoobladatel': Gosudarstvennoe obrazovatel'noe uchrezhdenie vysshego professional'nogo obrazovaniya "Voronezhskij gosudarstvennyj universitet" (RU). Data registratsii: 21.04.2008. Nomer zayavki: 2008115682/15.

2. Atlas po meditsinskoj mikrobiologii, virusologii i immunologii, Pod red. A. A. Vorob'eva, A. S. Bykova, M., Meditsinskoe informatsionnoe agentstvo, 2003, $60 \mathrm{p}$.

3. GOST 2874-82 Voda pit'evaya, gigienicheskie trebovaniya i kontrol' za kachestvom. SanPiN 2.1.4.1116-02.

4. Kotel'nikova T.A.,/ Sorbtsionnye i khromatograficheskie protsessy, 2017, Vol. 17, No 5, pp. 916-922.
6. Котельникова Т.А., Кузнецов Б.В., Морева А.А. и др. // Сорбиионные и хроматографические прочессы. 2012. Т.12. № 2. C.295-303.

7. Котельникова Т.А., Кузнецов Б.В., Морева А.А и др. // Сорбиионные и хроматографические прочессы. 2012. Т. 12. № 4. С. 523-531.

8. Котельникова Т.А. // Журн. Физич. Химии. 2017. Т. 91. № 10. С. 1792-1798.

9. Байгубекова Т.А, Киселев А.В., Никитин Ю.С. // Кинетика и катализ. 1972. Т. 13. Вып. 3. С. 755-761.

10. Милько Е.С., Милько Д.М. // Прикладная биохимия и микробиология. 2014. Т. 50. № 4. С. 408-412.

11. Wierenga P.A., Meinders M.B.J., Egmond M.R. et al. // J. Phys. Chem. B. 2005. Vol. 109. No 35. pp. 16946-16952.

5. Greg S., Sing K., Adsorbtsiya, udel'naya povernost', poristost', Pod red. ch.-k. AN SSSR CHmutova K.V.. M.: Mir, 1970. S.225.

6. Kotel'nikova T.A., Kuznetsov B.V., Moreva A.A et al., Sorbtsionnye $i$ khromatograficheskie protsessy, 2012, Vol. 12, No 2, pp. 295303.

7. Kotel'nikova T.A., Kuznetsov B.V., Moreva A.A et al., Sorbtsionnye $i$ khromatograficheskie protsessy, 2012, Vol. 12, No 4, pp. 523531.

8. Kotel'nikova T.A., Zhurn. Fizich. KHimii, 2017, Vol. 91, No 10, pp. 1792-1798.

9. Bajgubekova T.A, Kiselev A.V., Nikitin Yu.S., Kinetika i kataliz, 1972, Vol. 13, No 3, pp. 755-761.

10. Mil'ko E.S., Mil'ko D.M., Prikladnaya biokhimiya i mikrobiologiya, 2014, Vol. 50, No 4, pp. 408-412. 
11.Wierenga P.A., Meinders M.B.J., Egmond M.R. et al., J. Phys. Chem. B, 2005, Vol. 109,

Котельникова Татьяна Александровна к.Х.н., старший научный сотрудник, кафедра физической химии, химический факультет Московского государственного университета им. М.В.Ломоносова, Москва, 8(495)529-25-72
No 35, pp. 16946-16952.

Kotelnokova Tatyana A. - Cand.Chem.Sci., the senior scientific employee, faculty of physical chemistry, chemical faculty of the Moscow state university it M.V.Lomonosova, Moscow, e-mail; takotelnikova@mail.ru 